\title{
Relation between Psychological Pertinacity and Personality Inventories NEO with Defense Mechanisms at Students
}

\author{
Chiman Ansari \\ Master of Degree Course in Clinical Psychology, Faculty of Psychology, Science \& Research Branch \\ Islamic Azad University, Ilam, Iran; Email: chiman.ansari@yahoo.com
}

\section{Shahram Mami}

Doctorate of Psychology, Faculty of Psychology, Science \& Research Branch Islamic Azad University, Ilam, Iran; Emaile: Shahram.mami@yahoo.com

\section{Doi:10.5901/mjss.2015.v6n6s6p32}

\section{Abstract}

The research aims to determine relation between psychological pertinacity and personality inventories NEO with defense mechanisms of students. The method was descriptive- correlative. The statistical society consisted of all students of Islamic Aazd University, Kermanshah Branch ( $N=9329)$. The sample has been selected from Morgan table by volume 360 people from said society as randomly and evaluated by psychological pertinacity questionnaire of Kobasa, defense style questionnaire and NEO 5 factors questionnaire. Then the data has been analyzed by statistical method (deviation, deviation standard, correlation and regression) by using SPSS software. The findings showed that psychological pertinacity and personality inventories predicated $39 \%$ of student defense mechanisms. Also, as for results of Alpha of variables, psychological pertinacity has the more share $(B=0 / 62)$ and intravenous personality inventories $(B=0 / 56)$ were other defense mechanisms. Based on findings, we can conclude that the stubborn persons control life affairs more and evaluate environment happenings as meaningful whereas, persons lack pertinacity involved inability, strange and threat. Absolutely, this insight plays vital role in manner of evaluation. Thus, it is effective to consider psychological pertinacity in life affairs of students.

Keywords: Psychological Pertinacity, Personality Specifications, Defense mechanisms, Students.

\section{Introduction}

Psychological pertinacity is personality structure which is derived from useful experiences during children. Psychological pertinacity is more than control, commitment and defiance and accelerates health and its continuation and enhances and educate optimism glance to mental stresses. The researches of psychological pertinacity showed that high level of psychological pertinacity has mediation effect on stress and is related with disease and depression. The study showed that the men with high psychological pertinacity exposed controlled disease has more health, regardless, they confront with negative stress and the methods lack health. (Jamhari, 2005). Personality psychology is interested in nature of human and personal differences, although the psychologists accepted similarities between persons and their attention is into difference from each other, example, why some of persons are success and other not? Personality theorists considered generality of human and tried to discuss complicated relation between different human actions each other. By considering emphasize on personal differences, how can we define generality of humans? This work is as well as judgment for people that mean if love someone it is because of his good personality. But for psychological scientists, personality is applied for recognizing study. Every definition from personality is about inventories which apply in this field. (Kavidar, 2007)

Defense mechanisms are unconsciousness and non arbitrary methods which applied (i) to negate by deny real and reduce anxiety and negative emotions to maintain personality integration. The experimental witness showed that defense mechanisms and styles are regulated in terms of hierarchal and compatibility mechanisms are pertain to bodily and mental outcomes and incompatibility are pertain to personality disorders and depression. (Seyedmohammadi, 2009). Defense mechanisms are efficient and inefficient in terms of confrontation with different forms of anxiety and type of action. Rooz and et al divided 20 defense mechanisms as neurotics and under growth based on hierarchal classification of Villand abut defense mechanism. Freud believed that self is not inability in confrontation with outer world and anxiety informs person from danger, example, about sever conflict or lacking acceptance. If direct action doesn't control anxiety, 
the means the want doesn't satisfy, thus self applies unconsciousness defense to remove the conflict. Sum of defense respondents are possible. Since someone experiences danger, naturally, use of defense mechanism is not conforming behaviors. In case of anxiety and in order to reduce stress, defense mechanism is applied whether as lonely or with other mechanisms depends on it. (Milami far, 2005)

Victor Frankel ${ }^{1}$ one of the noble European psychologists in finding respond to it concluded that is life has meaning for persons; pressure due to it is tolerable. Life pressure situations can be effective on ability of persons with different situations and continuation of hard situations cause or intensify bodily and mental disorder. (Jomheri, 2005). Based on above, the researcher is following to find scale of relation between psychological pertinacity and personality inventories of defense mechanism between students.

\section{Methodology}

The research method is descriptive- correlative. The statistical society consisted of all students of Islamic Azad University, Kermanshah Branch ( $\mathrm{N}=9329)$. The society has been selected by Morgan table by volume 360 people of society and as randomly and analyzed by Kobayasa psychological pertinacity questionnaire and defense questionnaire and NEO 5 factors personality. Then the data have been analyzed by statistical methods (average, deviance, correlation and regression) by using SPSS software.

\subsection{Research Tools}

1) Personal Insight Questionnaire: Personal Insight Questionnaire has been used for estimation of pertinacity. This scale has been made by Kobayasa (1986, narrated by Ghorbani 1994) and consists of 50 articles with three micro scales like commitment, control and defiance which belong to 16, 17, 17 articles. Ghorbani 1994, estimated validity estimation in an introductory study on 110 Iranian women for 50 articles as 0/74 and 0/70. Validity estimation for defiance and control was 0/65 and 0/68. Besharat at 2005 reported alpha coefficient from 0/88 till 0/93 for subscales of commitment and from 0/85 till 0/94 from control from 0/89 till 0/95 for defiance and from $0 / 78$ to $0 / 94$ for total point of pertinacity which shows good internal compatibility. Correlation coefficient was two in four distances from 0/82 till 0/90 for commitment and from 0/80 till 0/88 from control and from 0/79 to 0/87 from defiance and from 080 to 0/88 for total point of pertinacity which sufficient reexamination efficient for scale. (Besharat, 2005)

2) 5 factors questionnaire of NEO: in order to collect data for estimating personality specifications, NEO questionnaire has been used which has been provided by Mckery and Costa 1992 for measuring 5 main personality factors (painful, suitability introspection, flexibility and responsibility). In this questionnaire, respond to questions are as four options like completely accept, accept, rejection and completely rejection). Haghshenas 2006, obtained internal stability based on alpha coefficient for indicators like painful, introspection, flexibility, suitability and responsibility.

3) Defense Style Questionnaire (DSQ): defense style questionnaire has 40 questions and 20 defense mechanisms in terms of growth defense style, neurotics and under growth. Alpha cronbach coefficient for growth, neurotics and under growth is 0/75, 0/73 and 0/74. Validity reexamination coefficient is obtained. (Andrews, Sing and Bound 1993). There is significant coefficient between questionnaire and interest. In other word, the persons who have mature defense style and persons who have unsafe defense style use immature defense style. In research of Rezzadeh, 1991, alpha Kronbach coefficient is obtained as 0/84. (Rezazadeh 1991).

\section{Findings}

Table 1. Descriptive indicators, average and deviance of variables

\begin{tabular}{|l|l|c|c|c|}
\hline Variables & Indicators & Numbers & Average & Deviance \\
\hline \multirow{4}{*}{ Personality Specifications } & Painful & 360 & 17.25 & 4.06 \\
\cline { 2 - 5 } & Retrospection & 360 & 32.57 & 4.64 \\
\cline { 2 - 5 } & Responsibility & 360 & 31.41 & 4.29 \\
\cline { 2 - 5 } & Compatibility & 360 & 25.38 & 3.16 \\
\cline { 2 - 5 } & Acceptance & 360 & 35.59 & 4.58 \\
\hline
\end{tabular}




\begin{tabular}{|l|l|c|c|c|}
\hline & Psychological Pertinacity & 360 & 98.36 & 15.12 \\
\hline \multirow{4}{*}{ Defense Mechanisms } & Mature & 360 & 31.26 & 7.19 \\
\cline { 2 - 5 } & Immature & 360 & 44.65 & 10.38 \\
\cline { 2 - 5 } & Painful & 360 & 26.41 & 6.11 \\
\hline
\end{tabular}

Table 1. Descriptive indicators, average and deviance of psychological pertinacity, personality inventories and defense mechanisms of students.

Table 2. Correlation matrix between psychological pertinacity with personality inventories of NEO between students

\begin{tabular}{|l|c|c|c|c|c|}
\hline Variables & \multicolumn{5}{|c|}{ Personality Specifications } \\
\hline \multirow{2}{*}{ Psychological Pertinacity } & Painful & Introspection & Responsibility & Compatibility & Acceptance \\
\cline { 2 - 7 } & 0.06 & 0.19 & 0.39 & 0.16 & 0.36 \\
\hline
\end{tabular}

As displayed in table 2, there is positive and significant relation between psychological pertinacity and personality inventories (introspection, responsibility, compatibility and acceptance). But there is not significant relation between psychological pertinacity and personality inventory (painful).

Table 3. Correlation matrix between psychological pertinacity and defense mechanisms in students

\begin{tabular}{|c|c|c|c|}
\hline \multirow{2}{*}{ Variables } & \multicolumn{3}{|c|}{ Defense mechanism } \\
\hline & Mature & immature & painful \\
\hline Psychological defense & 0.34 & -0.14 & 0.03 \\
\hline
\end{tabular}

As table 3 showed, psychological pertinacity has significant relation with immature defense mechanisms and negative relation with mature defense mechanisms. But there is not relation between psychological pertinacity with defense mechanisms in students.

Table 4. Correlation matrix between NEO personality inventories with defense mechanism of students

\begin{tabular}{|l|c|c|c|}
\hline & \multicolumn{4}{|c|}{ Dariables } & \multicolumn{3}{|c|}{ Defense mechanisms } \\
\hline Painful & Mature & Immature & painful \\
\hline Introspection & -0.08 & 0.18 & 0.41 \\
\hline responsibility & 0.45 & -0.29 & 0.11 \\
\hline Compatibility & 0.25 & 0.12 & 0.03 \\
\hline Acceptance & 0.19 & -0.28 & -0.8 \\
\hline
\end{tabular}

As table 4 shows, there is significant relation between personality inventories (introspection, responsibility, compatibility and acceptance) with mature defense mechanisms in students. Also, there is negative and significant relation between immature defense mechanism and personality inventories in students (retrospection, compatibility and acceptance). There is positive and significant relation between painful with immature defense mechanisms. But there is not relation between personality inventories (retrospection, responsibility, compatibility, and acceptance) with defense mechanisms.

Table 5. Table for multiple regressions between psychological pertinacity and personality inventories with defense mechanisms in students

\begin{tabular}{|l|c|c|c|c|c|c|c|}
\hline Predication variables & $\mathrm{F}$ & $\mathrm{P}$ & $\mathrm{R}$ & $\mathrm{R}^{2}$ & $\mathrm{~B}$ & $\mathrm{~T}$ & $\mathrm{P}$ \\
\hline Psychological Pertinacity & & & & & 0.62 & 2.95 & 0.04 \\
\hline Acceptance & & & & & 0.48 & 3.55 & 0.00 \\
\hline Introspection & & & & & 0.56 & 4.70 & 0.00 \\
\hline Responsibility & 14.55 & 0.00 & 0.63 & 0.39 & 0.31 & 2.95 & 0.03 \\
\hline
\end{tabular}




\begin{tabular}{|l|l|l|l|l|l|l|c|}
\hline Compatibility & & & & & 0.28 & 1.36 & 0.09 \\
\hline Painful & & & & & -0.11 & -0.97 & 0.039 \\
\hline
\end{tabular}

As displayed in table 5 , regression $(R=0.63)$ shows that psychological pertinacity and personality inventories predicated $39 \%$ of defense mechanism of students and $\mathrm{F}$ is meaningful in level $1 \%$. Also, as for alpha results, variables of alpha $\mathrm{B}=0 / 62$ and retrospection $\mathrm{B}=0 / 56$ were another predicators in using defense mechanism.

\section{Discussion and Concluding}

As displayed in table 2, there is positive and significant relation between psychological pertinacity (retrospection, responsibility, compatibility and acceptance) in students but there is not relation between psychological pertinacity with personality inventories (painful). Thus, personality has important role in all aspects of life. Human is incredible persons and has special needs, values, beliefs and expectations which form his personality and it is determinate. Human is trying to find his needs and satisfy his needs with working. He spends his energy in suitable method and improves social relation with others. Also, he shows manner of mind and considers special selection. This finding is conforming to results of other researches. Nakhoda 2009, showed in research that psychological pertinacity with mental disease. It means more psychological pertinacity in person; he exposes mental disease little, and if his pertinacity point is little, the possibility of disease is more. Also, Morzaee and Hatami 2010, discussed that between 5 personality factors, introspection, delicious and happiness has negative relation with painful.

As displayed in table 3, psychological pertinacity has negative and significant relation with immature defense mechanisms and there is significant relation between mature defense mechanism and psychological pertinacity in students. Thus, defense mechanism is regarded as temporary restoration which causes reduction of anxiety and its misuses and gives better compatibility with unsuitable factors of environment. Defense mechanism is applied for indirect satisfaction of needs for thought, action and reaction which solves the problems. Sometime, there is conflict for satisfaction of inclinations and needs of self and self can play mediation role and use tools for reduction anxiety.

As displayed with table 4, there is positive and significant relation between personality inventories (introspection, responsibility, compatibility, and acceptance) with defense mechanism in students. Also, there is negative and significant relation between personality inventory (retrospection, compatibility and acceptance) with immature defense mechanism in students. There is positive and significant relation between painful with defense mechanisms of students. But there is not significant relation between personality inventories with painful of students. This finding is conforming to results of others. Hesamoddin Khazaee 2007 showed in his research that there is significant relation between mental disorders, bodily complaint, compulsory obsession, sensitivity in interpersonal relations, anxiety, aggressive, paratroide, psych, extra questions there is not significant relation between mental disorders and defense mechanisms but negation of correlative coefficient showed that the persons who exposed mental disorders use mature defense mechanisms. Pakdaman 2008 recognized relation between self loving and manner use of defense mechanisms in research. The partial analysis showed that relation of vulnerable self loving with immature defense mechanisms and painful with immature defense was positive and significant. Also results of Sheldon and Kasser 2006 on persons 17-82 years old, it was recognized that older men apply more experienced defense mechanisms, age and use of them to younger. Use of immature mechanisms predicated denial and increment event in neurotics personality and reduce compatibility. Felmimg j 2011 showed that there is positive and significant relation between defense mechanism and social behaviors of students and there is significant relation between replaced defense and non social behaviors.

Thus, Kobasa distorted pertinacity as combination of belief by using existentialism theory on personality which consisted of control, commitment and defiance. A person who has high commitment knows importance of who does activity and can find what he does and stimulates the pry. These persons combine some of life aspects like occupation, family, interpersonal relations. Some others have control indicator and predicate life events and believed in and are able to influence what happen around. These persons emphasize upon their responsibility for solving problems. The persons have high defiance need positive and negative situations for compatibility again till threat for calmness and security, this belief is with cognitive flexibility and toleration power of unhappy events. Thus, defense mechanism is auto regulation processes which act based on reduction of cognitive inconsistency, and minimize abrupt changes in internal and external fact by influencing on manner of threaten events. Defense mechanisms are similar but they have shared elements, first, there are self seducement and flee from fact and other defense operations are conflict with problematic. Firstly, a person who excuse for it cannot aware from it and compromise is due to transaction of feelings and emotions, naturally, it is impossible for someone who hides in trench. 


\section{References}

Pakdaman Shahla, 2008, Styles of Defense Mechanism in types of Self loving personality, consulting and psych Journal, period 13, no,3 Parvin Kadivar, 2007, personality Psychology, Tehran, Arasbaran Press

Jomharai Farhad, 2005, Discussion Relation between Pertinacity and Psychology and trend into depression and anxiety between students men and women of Tehran Universities, Doctorate Thesis, Alame Tabatabaei University

Haghshenas Hassan, 2006, 5 Factors for personality Specifications, Guidance for interpretation and Norms, Shiraz Medical Sciences University Press

Khazaee Hesamoddin, 2007, Discussion Relation between Mental Disorders and Defense Mechanism, Students of Payam-e-Nour Univeristy, Torbat Jam Branch, master Degree Thesis not published

Richard P. Haljin Suzan Cross Witburn, 2002, Mental Pathology, second volume, translate by Yahya Seyedmohammadi, 2009, Ravan Press

Fist Hesbi, Fist Gregory 20002, Personality Theories, translate by Yahya Seyedmohammadi, 2009, Ravan Press

Ghorbani Nima 1994, Discussion relation between behavioral pattern of type A, behaviors for Heart croner disease and pertinacity, Master Degree thesis of Tarbiat Modarres Univeristy

Mirzaee Forogh, Hatami Hamidreza, Relation of personality and happinees in students, Thought and Behavior, applied psychology, autumn 2010, 47-56: 17(5)

Milanifar Behrouz, 2005, Mental Health, 20th press

Nakhoda Nasim, 2009, Discussion simple and multiple relation of pertinacity and social support with mental and bodily health of male teachers on Shushtar, Master Degree Thesis, not published

Andrews G, Singh M, Bond M. The Defense Style Questionnaire. J Nerv Ment Dis. 1993; 181(4):246-56.

Andrews, G., Singh, M., \& Bond, M. (1993). The Defense Style Questionnaire. Journal of Nervous and Mental Disease, 181(4): 246-256.

Bagby, R. M., Parker, J. D. A., \& Taylor, G. J. (1994). The twenty-item Toronto Alexithymia Scale: I Item selection and cross-validation of the factor structure. Journal of Psychosomatic Research, 38(1): 23-32

Besharat MA, tashak Anahita, Rezazadeh MR. Explaning marital satisfaction and mental health in terms of coping styles. Contemporary Psychology 2005;1(1).

Besharat, M. A. (2007). Reliability and factorial validity of Farsi version of the Toronto Alexithymia Scale with a sample of Iranian students. Psychological Reports, 101(1): 209-220.

Besharat, M. A. (2010). Relationship of alexithymia with coping styles and interpersonal problems. Procedia Social and Behavioral Sciences, 5: 614- 497.

Besharat, M. A. (2011). Development and validation of Adult Attachment Inventory. Procedia - Social and Behavioral Sciences 30: 475479.

Besharat, M. A., \& Shahidi, S. (2011). What is the relationship between alexithymia and ego defense styles? A correlational study with Iranian students. Asian Journal of Psychiatry, 4: 145-149.

Bowlby, J. (1969). Attachment and loss: Vol. I. Attachment. New York: Basic Books.

Bowlby, J. (1973). Attachment and loss: separation. New York: Basic Books.

Bowlby, J. (1988). A secure base: clinical applications of attachment theory. New York: Basic Books.

Cramer, P. (2009). Personality, personality disorders, and defense mechanisms. Journal of Personality, 67(3): 535-551.

Fleming. G, M. D. S., Blehar, M. C., Waters, E., \& Wall, S. (2011). Patterns of attachment: a psychological study of the strange situation. Hillsdale, NJ:Erlbaum.

Rezazadeh MR. relationship of attachment styles and relationship skills with marital consistency in the students of Tehran university. Tarbiat Modaress University, 1370.

Sheldon and Kasser, T. (2006). Correlates and retrospectively reported antecedents of alexithymia. Psychosomatic Medicine, 56: 353359.

Thomas, J. (2010). Attachment and loss: sadness and depression. New York: Basic Books.

Costa, P. T, Jr, \&MeCrae, R. R. (1992). Revised NEO personality inventory (NEO-PI-R) and NEO five factor inventories (NEO-FFI) professional manual. Odessa, FL: psychological assessment resources. 